\title{
Período de armazenamento e da massa na germinação de sementes de mangueira da variedade Carabao
}

\author{
Juliana Altafin Galli * \\ Maria Beatriz Soares \\ Antônio Lucio Melo Martins \\ Apta Centro Norte (DDD/APTA/SAA), Caixa Postal 24, CEP 15830-000 \\ Pindorama - SP, Brasil \\ * Autor para correspondência \\ julianagalli@apta.sp.gov.br
}

Submetido em 30/08/2011

Aceito para publicação em 31/05/2012

\section{Resumo}

A mangueira é considerada uma espécie que produz sementes recalcitrantes, que possuem problemas com o armazenamento. O objetivo do trabalho foi avaliar o efeito do período de armazenamento e da massa na germinação de sementes de mangueira Carabao. Os frutos foram colhidos e os caroços colocados para secar. As sementes foram pesadas e separadas em duas classes: I, com massa de até 19,0g, e II, acima de 19,0g, tratadas com Thiabendazol $60 \%$, embaladas em sacos transparentes de polietileno perfurados, e mantidas no laboratório. As sementes foram postas para germinar diretamente em sacos plásticos. $\mathrm{Na}$ análise estatística utilizou-se o delineamento em blocos casualizados, com quatro repetições, que consistiram de cinco períodos de armazenamento: 0 (zero), 7, 14, 21 e 28 dias. Também foi realizada a análise de regressão. Devido ao pequeno número de sementes com massa inferior a 19,0g, a germinação com separação de classes foi realizada somente nos períodos de zero e sete dias de armazenamento. Concluiu-se que as sementes de manga da variedade Carabao, tratadas com fungicida, apresentam melhor desempenho semeadas após sete dias de armazenamento em sacos de polietileno e que a massa das sementes de manga influi positivamente na sua germinação.

Palavras-chave: Mangifera indica L.; Sementes recalcitrantes

\section{Abstract}

Effects of storage period and mass on seed germination of the Carabao mango. The mango is a species that produces recalcitrant seeds, which can be difficult to store. The objective of this work was to evaluate the effect of storage period and mass on the germination of Carabao mango seeds. The fruits were picked and the pits were dried. The seeds were weighed and separated in two classes: I) with a mass up to $19.0 \mathrm{~g}$, and II) above $19.0 \mathrm{~g}$. The seeds were treated with $60 \%$ thiabendazol, wrapped in perforated transparent polyethylene bags, maintained in a laboratory, and germinated directly in the plastic bags. The statistical analysis used a randomized block design, with four repetitions, that consisted of five storage periods: 0 (zero), 7, 14, 21 and 28 days. A regression analysis was made. Due to the small number of seeds with a mass less than $19.0 \mathrm{~g}$, the germination tests using two classes were done only for the periods of zero and the first seven days of storage. It was found that the seeds of Carabao mango, when treated with fungicide, performed best when sown after seven days of storage in polyethylene bags, and that the mass of the seeds positively influenced germination.

Key words: Mangifera indica L.; Recalcitrant seeds 


\section{Introdução}

A manga (Mangifera indica L.) é uma das principais frutas tropicais produzidas no Brasil. Sua propagação deve ser feita de forma assexuada, restringindo-se o uso de sementes a obtenção de porta-enxertos. A variedade Carabao demonstra ser um excelente porta-enxerto para mangueira. Além de ser resistente aos dois biótipos de Ceratocystis fimbriata, agente causal da seca-damangueira, suas sementes podem ser retiradas do interior do endocarpo com muita facilidade e germinam muito bem (PINTO, 2004).

A mangueira é considerada uma espécie que produz sementes recalcitrantes (ROBERTS, 1972). As sementes recalcitrantes apresentam maiores dificuldades no armazenamento quando comparadas com as sementes ortodoxas. Isto se deve a sua alta suscetibilidade a perda de água, o que faz com que seja necessário o armazenamento com alto grau de umidade. Esta umidade interna favorece o ataque de microrganismos e germinação durante o armazenamento (KING; ROBERTS, 1979).

Segundo Mancin et al. (2004), o período que vai desde a colheita do fruto, obtenção da semente e semeadura, não deverá ultrapassar de 15 a 30 dias, visto que as sementes perdem seu poder germinativo com relativa rapidez, devendo a época de semeadura coincidir com a da colheita dos frutos. Com base na literatura revisada, observa-se que o método mais indicado e que resulta em maior porcentagem de germinação é o do uso de sementes sem endocarpo, as quais, após o completo preparo, devem ser imediatamente semeadas (CHAURAN et al., 1979; MANICA, 2001; MANCIN et al., 2004).

Para Bonner (1978), as sementes recalcitrantes se conservam melhor em sacos de polietileno, pois as perdas de água são evitadas. O mesmo autor, porém, não recomenda o uso de recipientes herméticos. Alguma troca gasosa deve ocorrer entre as sementes e a atmosfera, pois com altos teores de umidade, a respiração das sementes ocorre em altas taxas, e o bloqueio destas trocas pode causar a morte das sementes.

Além dos problemas com o armazenamento já apontados, as espécies recalcitrantes enfrentam uma dificuldade adicional. Por serem pouco estudadas, muitas delas não são contempladas nas Regras de Análise de Sementes nacionais (BRASIL, 1992) e internacionais (DRAPER, 1985). A inclusão destas espécies nas referidas regras deve ser uma meta a atingir, pois isto viria a facilitar, sobretudo, os trabalhos de pesquisa e testes de qualidade, através de resultados mais confiáveis e comparáveis entre si (NEVES, 1994).

São escassos os trabalhos que abordam a influência da massa das sementes de manga na germinação. Moraes (1989) recomenda a separação e classificação das sementes de mangueira por peso ou tamanho, porque, segundo o autor, as mais pesadas destacam-se por serem mais vigorosas.

Diante do exposto, o objetivo do presente trabalho foi avaliar o efeito do período de armazenamento e da massa das sementes na germinação de sementes de mangueira Carabao.

\section{Material e Métodos}

O trabalho foi conduzido na Apta Pólo Centro Norte, em Pindorama-SP. Os frutos de manga da variedade Carabao foram colhidos de diferentes árvores da mesma idade, em completo estado de maturação, em dezembro de 2008. Após a colheita dos frutos maduros, estes foram colocados em um tanque com água e procedeu-se, com o auxílio de um canivete, a retirada da casca e da polpa, seguida da lavagem das sementes. Os caroços foram colocados sobre folhas de jornal, para secagem em local sombreado e ventilado, por três dias.

Em seguida, realizou-se a extração do tegumento externo que envolve a amêndoa, com o auxílio de tesoura de poda. Foram descartadas as sementes quebradas e defeituosas. As sementes foram pesadas individualmente, e separadas em duas classes: classe I, com massa de até $19,0 \mathrm{~g}$, e classe II, sementes com massa acima de 19,0g.

Após a pesagem, todas as sementes foram tratadas com Thiabendazol 60\% (2g/kg de sementes) sendo, em seguida, embaladas em sacos transparentes de polietileno, perfurados, e mantidas no laboratório, em temperatura ambiente. As sementes do tratamento 
0 (zero) foram levadas diretamente para o meio de germinação.

As sementes foram postas para germinar, independente da massa (classe I e II), deitadas com a face ventral para baixo, diretamente em sacos plásticos de polietileno de $34 \mathrm{~cm} \times 17 \mathrm{~cm}$, com orifícios no terço inferior para escoamento do excesso de água. O substrato utilizado foi solo de barranco. As sementes foram cobertas com uma camada de palha, para proteção da insolação direta.

$\mathrm{Na}$ análise estatística utilizou-se o delineamento em blocos casualizados, com quatro repetições de 50 sementes por tratamento. Os tratamentos $(\mathrm{T})$ consistiram de cinco períodos de armazenamento das sementes: 0 (zero), 7, 14, 21 e 28 dias. Os dados foram submetidos à análise de variância pelo teste $\mathrm{F}$, e as médias dos tratamentos foram comparadas entre si pelo teste de Tukey, ao nível de 5\% de probabilidade. Também foi realizada a análise de regressão, testando-se os modelos linear, quadrático, cúbico e o desvio da regressão, e as equações foram selecionadas utilizando-se o teste $\mathrm{F}$.

Devido ao pequeno número de sementes com massa inferior a 19,0g, a germinação com separação de classes de sementes foi realizada somente em dois períodos, aos zero e sete dias de armazenamento, e foram avaliados separadamente, em outro ensaio, em delineamento fatorial 2 × 2 (classes de sementes I e II x 2 períodos de armazenamento).

\section{Resultados}

As porcentagens de germinação das sementes nos diferentes períodos de armazenamento encontram-se na Tabela 1. Verifica-se que a maior porcentagem foi observada nas sementes armazenadas por 28 dias, sem diferir significativamente das sementes armazenadas por sete dias.

A Figura 1 ilustra o comportamento cúbico do efeito do armazenamento sobre a porcentagem de germinação, atingindo o ponto máximo aos 28 dias de armazenamento.
TABELA 1: Porcentagem media de germinação de sementes de manga da variedade Carabao nos diferentes períodos de armazenamento.

\begin{tabular}{cc}
\hline $\begin{array}{c}\text { Tratamentos } \\
\text { (dias de armazenamento) }\end{array}$ & \% germinação \\
\hline 0 & $36,5 \mathrm{~b}^{1}$ \\
7 & $50,5 \mathrm{ab}$ \\
14 & $34,0 \mathrm{~b}$ \\
21 & $47,5 \mathrm{~b}$ \\
28 & $68,0 \mathrm{a}$ \\
\hline F Tratamentos & $\mathbf{9 , 1 3}{ }^{\text {*** }}$ \\
C.V. (\%) & $\mathbf{1 8 , 8 5}$ \\
\hline
\end{tabular}

${ }^{1}$ Médias seguidas pela mesma letra não diferem entre si, pelo teste de Tukey, a $5 \%$ de probabilidade. ${ }^{* *}$ Significativo, a $1 \%$ de probabilidade.

FIGURA 1: Efeito do período de armazenamento de sementes de manga da variedade Carabao na porcentagem de germinação. * Significativo a $5 \%$ de probabilidade pelo teste F.

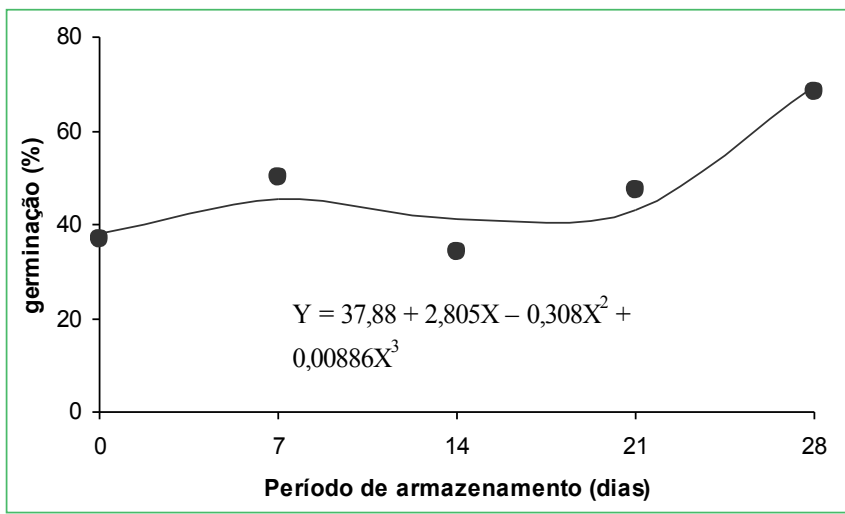

Na Tabela 2 se encontram os resultados da germinação das sementes separadas por massa, aos zero e sete dias de armazenamento. Verificou-se que não houve interação significativa entre a massa de sementes e os períodos de armazenamento, e que para ambos períodos as sementes mais pesadas (acima de 19,0g) apresentaram as melhores porcentagens de germinação. 
TABELA 2: Efeito da massa de sementes de manga da variedade Carabao na porcentagem de germinação em dois períodos de armazenamento.

\begin{tabular}{lcc}
\hline \multirow{2}{*}{ Classe de sementes } & \multicolumn{2}{c}{ Período de armazenamento (dias) } \\
\cline { 2 - 3 } & \multicolumn{1}{c}{$\mathbf{0}$} & 7 \\
\hline I (até 19,0g) & $28,0 \mathrm{~B} \mathrm{~b}^{1}$ & $37,0 \mathrm{~A} \mathrm{~b}$ \\
II (acima de 19,0g) & $45,0 \mathrm{~B} \mathrm{a}$ & $71,0 \mathrm{~A} \mathrm{a}$ \\
\hline F (classe) & \multicolumn{2}{c}{$24,47^{* *}$} \\
F (armazenamento) & \multicolumn{2}{c}{$11,23^{* *}$} \\
F (classe x armaz.) & \multicolumn{2}{c}{$3,07^{\mathrm{NS}}$} \\
C.V. (\%) & \multicolumn{2}{c}{22,98} \\
\hline
\end{tabular}

${ }^{1}$ Médias seguidas pela mesma letra maiúscula nas linhas e minúscula nas colunas, não diferem entre si, pelo teste de Tukey, a $5 \%$ de probabilidade. ${ }^{* *}$ Significativo, a $1 \%$ de probabilidade; ${ }^{N S}$ não significativo.

\section{Discussão}

Contrariando o senso comum, de que sementes de manga devem ser germinadas imediatamente após a retirada da polpa, as sementes que apresentaram maior porcentagem de germinação foram as que ficaram armazenadas por mais tempo (28 dias). Essa maior germinação deveu-se pelo fato das sementes terem pré-germinado dentro dos saquinhos, devido as condições de calor e umidade durante os 28 dias de armazenamento, e, portanto, quando foram semeadas, germinaram mais rápido do que as sementes dos outros tratamentos, que permaneceram menos tempo nestas condições, o que funcionou como um mecanismo de escape contra a ação dos patógenos de solo e fungos de armazenamento. Em todos os tratamentos, as sementes que não germinaram apresentaram os cotilédones escuros e algumas apresentaram infecção por fungos do gênero Aspergillus sp. e Penicillium sp., apesar de terem recebido o tratamento fungicida. A pré-germinação das sementes no armazenamento acelerou o processo de germinação no substrato, o que fez com que as sementes não permanecessem muito tempo no solo sendo atacada pelos patógenos.

Wang (1989) observou que sementes de manga, imediatamente após a extração, oxidam-se rapidamente, provocando um escurecimento nos cotilédones, fato que também foi observado no presente experimento. Vários autores recomendam a semeadura da mangueira logo após a colheita para evitar perdas no vigor (ITO; ATUBRA, 1973; CHAURAN et al., 1979; MORAES, 1989; SÃO JOSÉ; SOUZA, 1992; CUNHA et al., 1994). No presente trabalho, as maiores porcentagens de germinação ocorreram aos sete e 28 dias de armazenamento, sendo este último decorrente da pré-germinação das sementes, devido as condições de temperatura e umidade no interior dos saquinhos (Tabela 1). Borges et al. (2003), avaliando períodos de armazenamento e germinação de sementes de manga da variedade Espada, verificaram que para porcentagem de germinação e índice de velocidade de germinação os melhores resultados ocorreram aos 7,5 dias de armazenamento. Segundo os autores, o melhor desempenho das sementes pode ter sido acarretado por uma toxidez inicial provocada pelo fungicida, levando as sementes do período 0 (zero) a ter menor vigor. Garcia e Vieira (1994) verificaram o mesmo problema em sementes de seringueira tratadas com fungicida. Os dados do presente trabalho confirmam a hipótese de que sementes de manga tratadas possuem um melhor desempenho aos sete dias de armazenamento.

Na literatura há resultados controversos quanto à germinação de sementes de manga, podendo-se supor que deve haver diferenças entre variedades. Chauran et al. (1979) relataram que o plantio de sementes de manga Ubá, desprovidas do endocarpo e sem passar por um período de armazenamento, apresentou maior porcentagem de germinação, altura, diâmetro e número de folhas. Borges (1997) verificou que sementes de mangueira Ubá não devem ser armazenadas, e que a semeadura deve ser realizada logo após a coleta dos frutos e preparo das sementes. Por outro lado, AbdelGalil (1992) mostrou que as porcentagens de germinação de sementes com o tegumento removido após 10, 18 e 24 dias da extração do caroço foram de 39,78, 80,67 e $96,22 \%$, respectivamente, comparando com $0,11,1$ e $45,56 \%$ para sementes com o tegumento intacto.

A queda na porcentagem de germinação, aos 14 dias de armazenamento, com posterior recuperação aos 21 dias (Figura 1), também foi relatada por Borges et al. (2003), que verificaram, nas sementes de manga da variedade Espada de massa até $15,5 \mathrm{~g}$, que houve uma queda na germinação, no período de 14 dias, de 90 para $65 \%$, com posterior recuperação para $80 \%$ aos 
21 dias. No presente trabalho, a queda aos 14 dias, de 50 para $34 \%$ de germinação, ilustra o efeito deletério do armazenamento das sementes na perda do vigor. A posterior recuperação, aos 21 e 28 dias, deveu-se pelo fato das sementes se encontrarem pré-germinadas por ocasião da semeadura no substrato.

Girita e Srinivasan (2001) mostraram, para as condições da Índia, que sementes dos cultivares Neelem e Goa armazenadas em sacos de aniagem molhados, mantiveram a viabilidade por um período de no máximo 10 semanas. Chauran et al. (1979), ao estudarem o efeito do tempo de armazenamento sobre a germinação de sementes de mangas, constataram que a viabilidade é inversamente proporcional ao tempo de armazenamento. $\mathrm{O}$ índice de germinação aos 48 e 60 dias de armazenamento foi de 56,78 e $64,67 \%$ e aos 0 e 28 dias, foi de 97,5 e $95,67 \%$, respectivamente.

Também há bastante controvérsia na literatura quanto o efeito da massa de sementes de manga sobre sua germinação e vigor. No presente trabalho, as sementes da variedade Carabao, em ambos períodos de armazenamento, apresentou maior porcentagem de germinação para as sementes de maior tamanho (Tabela 2). Ao estudarem esse comportamento em sementes das variedades Ubá e Espada, Borges et al. (1998) não encontraram para o primeiro cultivar, efeito do peso da semente sobre a porcentagem de germinação, e com relação ao cultivar Espada, as sementes com peso acima de 19,0g mostraram maior poder germinativo. Contrariando esses resultados, em trabalho posterior, Borges et al. (2003) verificaram, para a cultivar Espada, que a massa das sementes não afeta a germinação, mas influencia a altura, o diâmetro do caule, o número de folhas e a massa da matéria seca da parte aérea. Degani et al. (1993) observaram que não houve correlação entre massa das sementes e germinação em mangas das cultivares Turpentine e 13-1.

Considerando os resultados obtidos, pode-se concluir que as sementes de manga da variedade Carabao, tratadas com fungicidas, apresentam melhor desempenho quando semeadas após sete dias de armazenamento em sacos de polietileno, e que a massa das sementes de manga influi positivamente na sua germinação.

\section{Referências}

ABDEL-GALIL, H. A. Evaluation of certain techniques for germination of mango seedstones. Assiut Journal of Agricultural Sciences, Warsaw, v. 23, n. 4, p. 137-151, 1992.

BONNER, F. T. Storage of hardwood seeds. Forest Genetic Resources Information, Rome, n. 7, p. 10-17, 1978.

BORGES, C. A. M. Caracterização biométrica de sementes, germinação e crescimento de plântulas das mangueiras (Mangifera indica L.) "Espada" e "Ubá”. 1997. 122 f. Dissertação (Mestrado em Agronomia) - Universidade Federal de Viçosa, Viçosa, 1997.

BORGES, C. A. M.; SIQUEIRA, D. L. de; DIAS, D. C. F. dos S.; CARDOSO, A. A. Influência do peso das sementes e da temperatura sobre a germinação e crescimento de plântulas das mangueiras Espada e Ubá. Revista Brasileira de Fruticultura, Jaboticabal, v. 20, n. 3, p. 272-282, 1998.

BORGES, C. A. M.; SIQUEIRA, D. L. de; DIAS, D. C. F. dos S.; CARDOSO, A. A. Influência da massa e do período de armazenamento das sementes na germinação e crescimento de mudas da mangueira "Espada". Pesquisa Agropecuária Brasileira, Brasília, v. 38, n. 8, p. 999-1004, 2003.

BRASIL. Ministério da Agricultura e Reforma Agrária. Regras para análise de sementes. Brasília: SNDA/DNDV/CLAV, 1992. 365 p.

CHAURAN, O. R.; MANICA, I.; PINHEIRO, R. V. R.; CONDE, A. R.; CHAVES, J. R. P. Efeito do tempo de armazenamento, corte e fungicida sobre a germinação das sementes e crescimento de plântulas de mangueira (Mangifera indica L.). Revista Ceres, Viçosa, v. 26, n. 143, p. 1-12, 1979.

CUNHA, G. A. P.; SAMPAIO, J. M. M.; NASCIMENTO, A. S.; SANTOS FILHO, H. P. S.; MEDINA, V. M. Manga para exportação: aspectos técnicos da produção. Brasília: Embrapa SPI, 1994. 35 p. (Produções Técnicas FRUPEX, 8).

DEGANI, C.; COHEN, M.; REUVENI, O.; EL-BATSRI, R.; GAZIT, S. Frequency and characteristics of zygotic seedlings from polyembrionic mango cultivars, determined using isozymes as genetic markers. Acta Horticulturae, Leuven, v. 341, p. 78-85, 1993.

DRAPER, S. R. International rules for seed testing 1985. Seed Science and Technology, Zurich, v. 13, n. 2, p. 299-355, 1985.

GARCIA, A.; VIEIRA, R. D. Germinação, armazenamento e tratamento de sementes de seringueira (Hevea brasiliensis Muell. Arg). Revista Brasileira de Sementes, Londrina, v. 16, n. 2, p. 128-133, 1994.

GIRITA, T.; SRINIVASAN, P. S. Effective short term storage technique for mango seed. Madras Agricultural Journal, Tamil Nadu, v. 87, p. 113-116, 2001.

ITO, P. J.; ATUBRA, O. K. Mango seed storage and propagation. Ghana Farmer, Kumasi, v. 17, n. 1, p. 34-38, 1973.

KING, M. W.; ROBERTS, E. H. The storage of recalcitrant seeds: achievements and possible approaches. Rome: International Board of Plant Genetic Resources, 1979. 196 p.

MANCIN, C.A.; MELO, B.; SOUZA, O. P. Cultura da mangueira. 2004. Disponível em <http://www.fruticultura.iciag.ufu.br/manga. html\#_TOC43654372>. Acesso em: 2 mar. 2009.

MANICA, I. Clima e solo. In: MANICA, I.; ICUMA, I. M.; MALAVOLTA, E.; RAMOS, V. H. V.; OLIVEIRA JR., M. E.; CUNHA, M. M.; JUNQUEIRA, N. T. V. (Ed.). Manga: tecnologia, 